\title{
Recursos informacionais abertos na área de química para estudantes do curso técnico de nível médio
}

\section{Open information resources for chemistry used by high school students from a technical course}

Recebido: 27/03/2020 | Revisado: 26/04/2020 | Aceito: 03/05/2020 | Publicado: 02/02/2021

\section{Rita Rodrigues Souza}

ORCID: http://orcid.org/0000-0002-05966985

Instituto Federal de Educação Ciência e Tecnologia de Goiás

E-mail: rita.souza@ifg.edu.br

Maria Aparecida Rodrigues de Souza ORCID: https://orcid.org/0000-0003-01735992

Instituto Federal de Educação Ciência e

Tecnologia de Goiás

E-mail: mcidarsouza@gmail.com

Como citar:

SOUZA, R.R.; SOUZA, M.A.R.; Recursos informacionais abertos na área de química para estudantes do curso técnico de nível médio. Revista Brasileira da Educação Profissional e Tecnológica, [S.I.], v. 1, n. 20, p. e9790, fev. 2021. ISSN 2447-1801.

This work is licensed under a Creative Commons Attribution 4.0 Unported License.

\section{Resumo}

Na sociedade da informação e do conhecimento, um número cada vez maior de dados é disponibilizado na Internet. Saber tratá-los, com fins profissionais e acadêmicos/escolares, é uma das habilidades básicas a ser desenvolvida no âmbito educacional. Nesse sentido, o objetivo geral desta pesquisa foi desenvolver uma ferramenta que facilitasse aos/às estudantes de cursos técnicos de nível médio a localização de recursos informacionais abertos para o desenvolvimento de pesquisas escolares. $O$ estudo foi desenvolvido por meio de revisão bibliográfica e mapeamento de recursos informacionais abertos disponíveis na Internet, na área de química. Após busca, recuperação e seleção das fontes informacionais, criamos um blog para armazenar e divulgar aos(às) estudantes o material selecionado. Os usos do blog, como repositório, bem como o acesso dele constituem 0 resultado da pesquisa.

Palavras-Chave: Tecnologia digital de informação e comunicação; Recursos educacionais abertos; Blog; Curso técnico de nível médio; Ciências Exatas e da Terra.

\begin{abstract}
It is known that a growing amount of data is being made available on the internet in the information and knowledge society. Knowing how to deal with them for professional and academic purposes is one of the basic skills to be developed in school. Hence, the overall objective of this research was to develop a tool in order to facilitate high school students from technical courses find open information resources so that they could research school content. The study was a bibliographic review that mapped the open information resources available on the internet regarding the subject of chemistry. After searching, retrieving and selecting information sources, a blog was set up in order to store and show students the selected material. The findings of this research revealed the use of blog as a repository and friendly user resource when it comes to its use and access.
\end{abstract}

Keywords: Digital information and communication technology; Open educational resources; Blog; High school technical course; Exact and Earth Sciences. 


\section{INTRODUÇÃO}

Um dos objetivos dos Institutos Federais de Educação Profissional e Tecnológica (IF) é o "desenvolvimento e difusão de conhecimentos científicos e tecnológicos", conforme Lei $n^{\circ}$. 11.892 de 2008. Assim, esses Institutos têm por missão o fortalecimento do processo de disseminação das informações e conhecimentos científicos e tecnológicos básicos, como também, fontes informacionais necessárias à educação científica e tecnológica dos(as) estudantes, inclusive, de nível médio.

Para além da disponibilização, há a necessidade de formar estudantes que saibam encontrar e, bem usar, as informações que precisam para solucionar problemas do cotidiano escolar, do contexto social extraescolar, questões de cunho político e econômico próximas à realidade deles(as). Paralelo a essa problemática, emergiu o seguinte problema de pesquisa: Como constituir um acervo digital para estudantes nativos digitais de um curso técnico de nível médio?

Em busca de resposta para a pergunta supracitada, escolhemos o públicoalvo referente ao Curso Técnico em Química, da área de conhecimento das Ciências Exatas e da Terra. O objetivo geral da pesquisa consistiu em organizar um acervo digital com conteúdos na área de Química a ser implementado nas bibliotecas do Instituto Federal de Educação, Ciência e Tecnologia de Goiás (IFG), de acesso aberto que atenda às necessidades de estudantes de nível médio.

A partir do problema de pesquisa e objetivo geral, fundamentamo-nos nos estudos de Coelho (2012) sobre as competências tecnológicas, Prensky (2002) e Santaella (2010) para discutir as pesquisas sobre nativos digitais, Souza (2017) para o procedimento metodológico e Marcondes, Kuramoto, Toutain e Sayão (2005) para tratar o papel das bibliotecas digitais.

Considerando a problemática aqui descrita, o presente artigo traz, inicialmente, uma discussão de implicações pedagógicas para o uso de tecnologias digitais para nativos dessa tecnologia, com ênfase no papel das bibliotecas. $\mathrm{Na}$ sequência, apresentamos a metodologia de pesquisa, os resultados e considerações sobre a trajetória da investigação, bem como aspectos que podem ser discutidos na mediação entre nativos digitais e o uso de tecnologias para a construção do conhecimento científico.

\section{FUNDAMENTANDO A PESQUISA: NATIVOS/AS DIGITAIS E BIBLIOTECAS (DIGITAIS)}

A consideração do público-alvo, do contexto sócio-histórico, das condições materiais objetivas e a atuação dos/as agentes educativos/as é fundamental para a proposição de ações educativas transformadoras e conectadas com o tempo e 
demandas do presente. É com esse pensamento que esta seção trata em duas subseções os/as nativos/as digitais e o papel das bibliotecas (digitais).

\subsection{NATIVOS/AS DIGITAIS: EXIGÊNCIAS DE MUDANÇA NA ATUAÇÃO PEDAGÓGICA ESCOLAR}

A característica predominante dos/as estudantes de nível médio, da sociedade da informação e do conhecimento, é ser nativo/a digital (SANTAELLA, 2010). Esse público nasceu e cresceu com as tecnologias digitais presentes na vivência dele. Desse modo, ratifica-se a relevância da investigação dessa problemática e propostas pedagógicas serem construídas a partir das necessidades desse público.

Identificamos, no âmbito da pesquisa teórica, tecnologias digitais como videogames, internet, dispositivos móveis, MP3, iPod etc. Elas caracterizam-se, principalmente, por serem tecnologias que não necessitam o uso de papel na execução de tarefas as mais variadas, desde estudo a atividades profissionais e de lazer.

As pessoas nascidas a partir da década de 90 são definidas, por Prensky (2001), como nativas digitais e apresentam familiaridade com o universo digital e com muitos dos usos da tecnologia como descrito anteriormente. Portanto, cabe aos/às educadores/as e pesquisadores/as atentarem para esse potencial e explorá-lo no processo de ensino e aprendizagem nos vários segmentos escolares e modalidades (presencial, semipresencial e on-line).

O século XXI, nomeado por Santaella (2010) como a sociedade digital, é marcado, principalmente, pelos avanços tecnológicos digitais e pela constituição do(a) cidadão(ã) digital. Coelho (2012) nos explica que os nativos digitais apresentam uma intimidade com os meios digitais e possuem a habilidade e competência de realizar múltiplas tarefas ao mesmo tempo. A geração desses/as nativos/os alterou, assim, definitivamente, os rumos da comunicação/interação, da educação também. Logo, não podemos pensar no acesso à informação e nem à educação sem considerar que os avanços tecnológicos digitais mudaram a forma de ser, agir e pensar da sociedade.

Os/As nativos/as digitais, segundo Prensky (2001), não se amedrontam diante dos desafios expostos pelas Tecnologias Digitais da Informação e da Comunicação (TDIC). Pelo contrário, experimentam e vivenciam múltiplas possibilidades oferecidas pelos aparatos digitais. Portanto, esse fascínio característico dessa geração pela descoberta e experimentação deve ser explorado pela escola, de maneira a direcionála para pesquisa interagindo com as múltiplas fontes digitais de informação.

A geração nativos/as digitais nasceu, cresceu e se desenvolveu em um período de grandes transformações tecnológicas digitais e, por suas correlações com esse meio digital, adquiriram competências e habilidades que lhes permitem desenvolverem diferentes atividades a partir desses novos meios de comunicação 
tecnológica (COELHO, 2012). Esses/as nativos/as digitais, muitas das vezes, optam unicamente pela realização de pesquisa utilizando as TDIC, cabendo ao professorado e, inclusive, às bibliotecas uma ressignificação do papel formativo que vêm desempenhando na formação dos/as estudantes. No âmbito deste artigo, abordaremos, a seguir, as bibliotecas digitais.

\subsection{BIBLIOTECAS (DIGITAIS): PAPEL FORMATIVO DOS/AS AGENTES QUE NELAS ATUAM}

Marcondes, Kuramoto, Toutain e Sayão (2005) defendem que as bibliotecas digitais são possibilitadoras da construção do conhecimento científico de maneira colaborativa, principalmente, se essas dispuserem de recursos educacionais abertos que favoreçam o compartilhamento e difusão da informação. Os recursos educacionais abertos representam materiais voltados ao processo de ensino e aprendizagem, dispostos de forma livre e aberta, que "têm como princípio a possibilidade de reuso e adaptação" (AMIEL; OREY; WEST, 2011, p. 121). Assim, disponibilizar esses recursos aos/às nativos/as digitais, nas bibliotecas, seria uma maneira de despertar o interesse desse público para o processo de pesquisa.

De maneira geral, uma biblioteca digital, por meio de sua fonte de informação, é um suporte ao ensino, à pesquisa e à extensão. Principalmente, se disponibiliza livremente, na Internet, tecnologias para o/a usuário/a editar e modificar o conteúdo, ou simplesmente usufruir do mesmo sem que precise desembolsar algum valor. Desse modo, as bibliotecas de instituições de ensino público, seja da educação básica ou superior, em qualquer parte do mundo, podem se utilizar desses recursos para possibilitar aos/às estudantes mais do que o acesso à informação.

No caso dos recursos educacionais abertos, o compartilhamento da informação adquire papel de suma importância, uma vez que o recurso exige estratégias, habilidades, competências e atitudes diferentes das fontes convencionais (SOUZA; OLIVEIRA, 2016). O Sistema de gerenciamento de acervo Sophia Terminal Web, adotado pelo SIB/IFG, por exemplo, tem recurso aberto, para o/a usuário/a logado/a no sistema, de copiar a referência, pré-formatada de acordo com as normas da Associação Brasileira de Normas Técnicas (ABNT), de interesse para uso, reuso e compartilhamento. Para uso desse recurso, o/a usuário/a deve apresentar alfabetização informacional e digital: saber que informação deseja, operacionalizar no computador, conhecer a funcionalidade do sistema, gerar a referência de interesse, verificar se está correta e/ou fazer as adaptações conforme a norma que for aplicar, compartilhar o recurso com quem queira.

A criação de bibliotecas digitais implica tanto na aquisição de habilidades e competências comunicativas por parte dos/as professores/as, bibliotecários/as e dos/as estudantes, quanto em uma preocupação com a criação de momentos de interação e de possibilidades concretas para a execução de trabalhos colaborativos, com os quais a aprendizagem ocorre de modo participativo. Logo, mais do que se 
pautar pela difusão de fontes tradicionais, é premente que o/a bibliotecário/a seja proativo/a no fornecimento e divulgação de recursos abertos, que podem contribuir favoravelmente com a formação e as pesquisas dos/as estudantes na biblioteca escolar.

Portanto, os recursos educacionais abertos precisam ser mais bem trabalhados na biblioteca escolar pelos/as bibliotecários/as. O papel dessa biblioteca, no contexto do ensino e da aprendizagem, demanda ação participativa no compartilhamento e difusão de novos recursos informacionais em formato digital. Para além disso, as bibliotecas necessitam desempenhar o papel de produtoras de conteúdo, recursos educacionais abertos, assumindo a postura de centros ativos que fomentem a educação e a produção de novos conhecimentos. Isto posto, passamos à explicitação da trajetória de pesquisa.

\section{METODOLOGIA: ESCOLHAS E CONSTRUÇÃO DA PESQUISA}

A presente pesquisa, de enfoque qualitativo e experimental, se iniciou por meio da fundamentação teórica e manteve-se nessa linha no decorrer de todo o processo investigativo. "Ela é, portanto, pesquisa bibliográfica" (SEVERINO, 1994, p. 65). De modo complementar, realizou-se um experimento que consistiu na elaboração e uso de um repositório digital no formato blog.

$\mathrm{Na}$ contemporaneidade, não somente os livros, mas também qualquer outra fonte de informação (jornal, revista, monografias, tutoriais, redes sociais etc.) apresentam em formato físico e/ou digital se constituem fontes para a pesquisa científica. Assim, o primeiro procedimento metodológico foi consultar o acervo de bibliotecas de uma instituição que oferta Curso Técnico Integrado Integral em Química de nível médio. Escolhemos o Sistema Integrado das Bibliotecas (SIB) do IFG pela facilidade de acesso aos dados pela Internet.

Ressaltamos que aos/às profissionais bibliotecários (as) cabem promover o uso dos "livros, enquanto instrumentos de trabalho didático e fontes de informação científica e, assim, úteis para a pesquisa [...]" (SEVERINO, 1994, p. 66). Às palavras de Severino (1994), acrescentamos que a esses/as profissionais também cabem usar, incentivar e instruir o uso de recursos da TDIC no fomento à leitura e à pesquisa.

Paralelamente ao levantamento e estudo bibliográfico, adaptamos o modelo de organização retórica proposto por Souza (2017) para a coleta de dados. Utilizamos os seis passos de movimento retórico de apresentação geral do conteúdo, de acordo com o exposto no Quadro 1: 
Quadro 1: Movimento retórico de apresentação geral do conteúdo

\begin{tabular}{|l|l|}
\hline \multicolumn{1}{|c|}{ Critérios } & \multicolumn{1}{c|}{ Características } \\
\hline Assunto & Refere-se ao conteúdo abordado no material, bem como objetivos e atividades. \\
\hline Publicação & Refere-se a quando o material foi publicado. \\
\hline Suporte & Refere-se ao lugar onde o material é veiculado, se impresso, digital ou online. \\
\hline Identificação & $\begin{array}{l}\text { Refere-se ao título e ao tipo da fonte: livro, apostila, vídeo, documentário, } \\
\text { experimentos. }\end{array}$ \\
\hline Público-alvo & Refere-se a quem está dirigido: $1^{\circ}, 2^{\circ}$ ou $3^{\circ}$ ano do ensino médio. \\
\hline Autor(a) & Refere-se a quem é o(a) autor(a) da fonte. \\
\hline
\end{tabular}

Fonte: Elaboração própria.

O uso dos movimentos retóricos possibilitou-nos a organização dos materiais selecionados de modo mais sistemático conforme objetivo da pesquisa. Para além disso, permitiu-nos uma dinamicidade na seleção e organização dos dados. Esse procedimento ocorreu durante a seleção e análise das fontes informacionais. Para tanto, foi criada uma planilha no Google drive, aplicativo on-line, que possibilitou compartilhar os dados entre as pesquisadoras.

Destacamos que foi criado um blog para postagem dos materiais selecionados. Houve, ainda, apreciação da ferramenta - blog - pelo público estudantil e docente na III Feira de Ciências do IFG/Câmpus Inhumas, ocorrida em 21 de novembro de 2019. Os/As participantes foram convidados/as pelas pesquisadoras a responder a um questionário com sete perguntas, sendo três fechadas e quatro abertas. Essas questões objetivaram coletar informações visando aprimorar 0 conteúdo e explorar mais as funcionalidades do recurso digital. As respostas dos participantes encontram-se nos resultados.

Nossos olhares preliminares, acerca do quadro de profissionais, apontam que há recursos humanos qualificados (Gráfico 1) no âmbito da Biblioteca Atena do IFG, Câmpus Inhumas, que podem contribuir para que a ação de implementar e gerir um acervo digital seja efetivada. 
Gráfico 1: Qualificação dos/as servidores/as da biblioteca

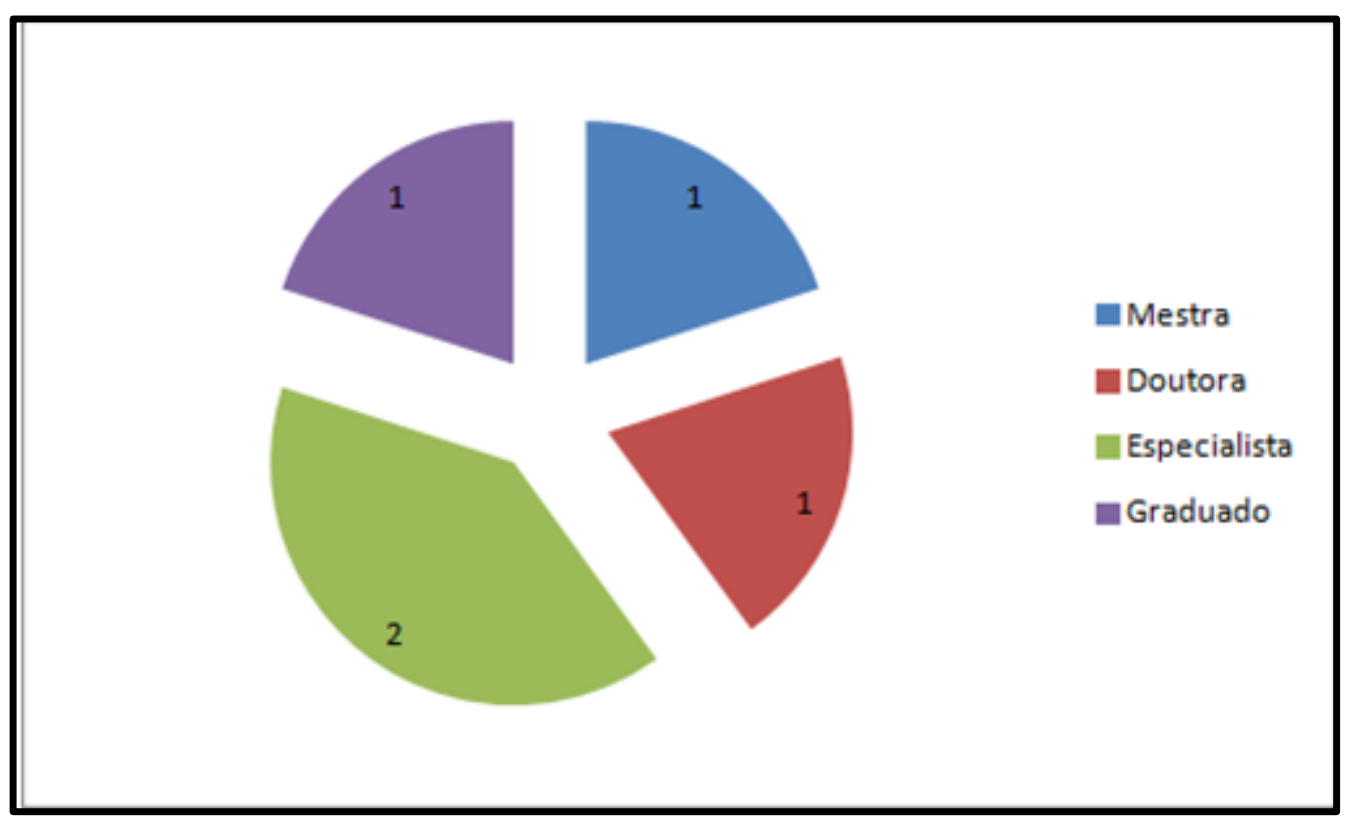

Fonte: Elaborado pelas pesquisadoras (2018)

Em síntese, visando alcançar os objetivos propostos, coletamos os recursos informacionais no formato digital e analisamos a possibilidade de acesso ao material. Os procedimentos foram: mapeamento sistemático das fontes e organização, criação e divulgação do blog e reflexão sobre a ação. Seguimos, na próxima seção, com os resultados.

\section{RESULTADOS E DISCUSSÕES: DO PROCESSO INVESTIGATIVO ÀS REFLEXÕES}

Apresentamos, nesta seção, uma síntese do mapeamento e organização das fontes de pesquisa disponíveis na Internet, de acesso aberto, na área de ensino de química para o público de nível médio. Para tanto, propomos a seguinte organização: 4.1 Do mapeamento, abordamos os resultados dos processos de busca e seleção; 4.2 Da criação e avaliação do blog, evidenciamos a dinâmica de criação do blog, bem como as diretrizes nas quais nos apoiamos para a escolhas feitas para a elaboração desse repositório; por fim, em 4.3 Da reflexão sobre a ação empreendida, elencamos nossas impressões dos resultados obtidos.

\subsection{DO MAPEAMENTO}

Inicialmente, simultânea à pesquisa de materiais de química, realizamos uma busca, via SIB/IFG, para verificar a existência de material digital indicado à estudantes 
de ensino médio. Também, mapeamos os materiais bibliográficos sobre metodologia científica encontrados e constatamos uma lacuna de produção bibliográfica referente a essa temática para o ensino médio. Por ser parte de uma instituição de ensino profissional tecnológico e científico, a criação de um repositório para disponibilizar informação científica, por meio do SIB, constitui uma possibilidade viável para disseminação de informações científicas e fomento à produção de conhecimentos.

Constatamos que, no acervo do SIB/IFG, no momento da pesquisa, tinham 185 materiais textuais impressos (livros didáticos e paradidáticos) para consulta na área de química indicados ao ensino médio. Ao mapear o acervo bibliográfico do SIB/IFG, visando conhecer realidade acadêmica, como locus para construção de conhecimentos científicos na escola, sem cair na armadilha da racionalidade técnica e sem transferir a função mediadora aos instrumentos, identificamos um acervo reduzido de livros para ensino médio na área de química, conforme ilustra a Figura 1:

Figura 1: Acervo de química indicado ao ensino médio

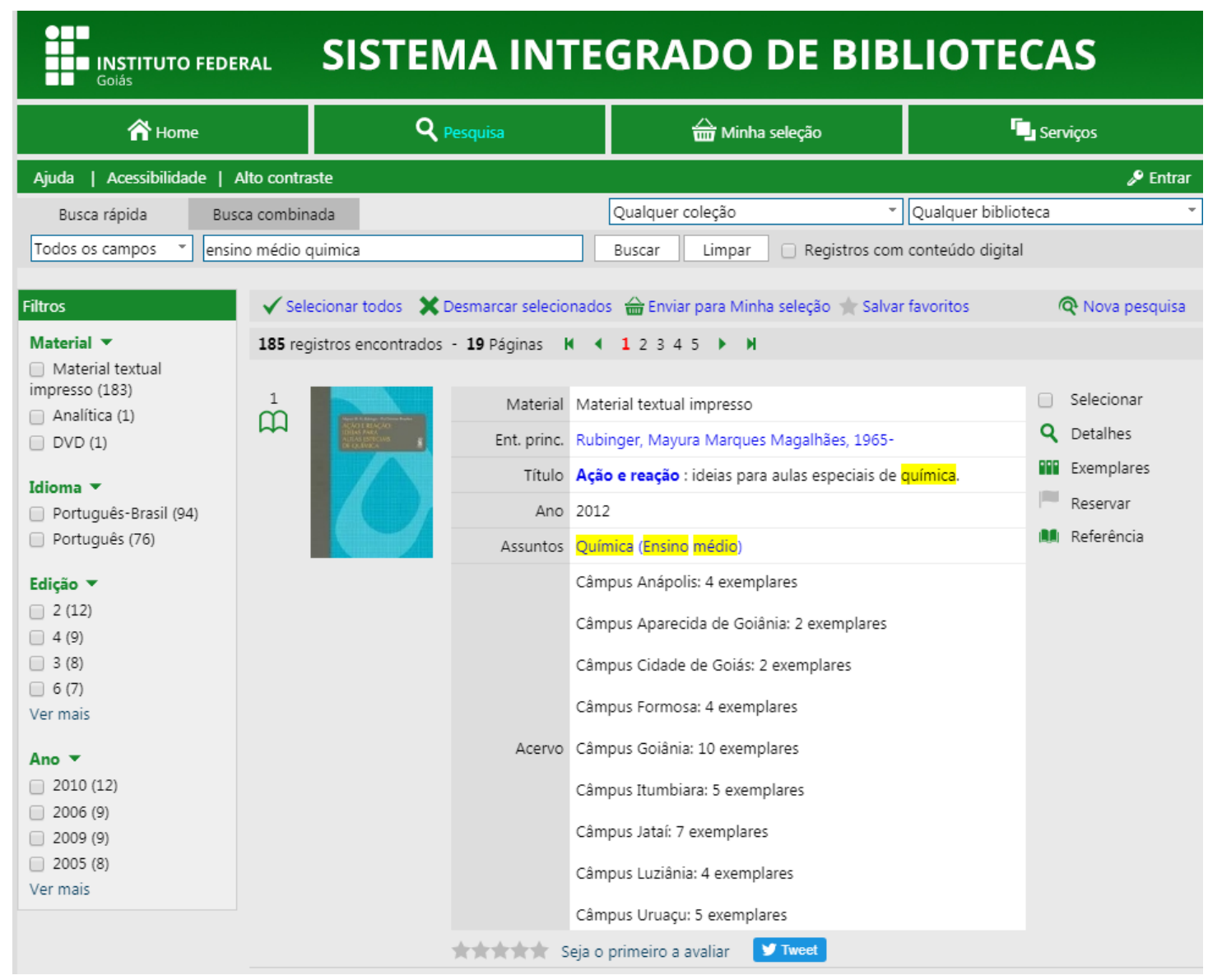

Fonte: Elaboração própria

O SIB disponibiliza aos/às estudantes em seu sítio o Portal de Periódicos Capes e a base de dados EBSCO HOST, material indicado ao ensino superior. Nesse sentido, o resultado das características dos materiais que encontramos não atendia 
às expectativas dos/as nativos/as digitais, apresentadas por Coelho (2012), Santaella (2010) e Prensky (2001), no quesito leitura/pesquisa pelo dispositivo móvel ou computador. Esse dado é salutar para a compreensão da necessidade de atualização do acervo e realização de novas práticas de atendimento na biblioteca da instituição.

O próximo procedimento foi a identificação de recursos educacionais de acesso aberto com possibilidade de compor o acervo do SIB/IFG. O interesse por recursos abertos visa resguardar os direitos autorais e a possibilidade de reuso e adaptação defendidos por Souza e Oliveira (2016) e Amiel, Orey e West (2011). Nessa perspectiva, aumentam-se as possibilidades de acesso à informação e uso da mesma de modo ético e, consequentemente, aumentam-se as possibilidades de produção de conhecimentos e inovação.

Concluído o mapeamento dos recursos informacionais abertos, para aplicação na área de química de nível médio disponível na Internet, iniciamos, enfim, a criação do blog para que tais conteúdos fossem disponibilizados aos/às estudantes e esses pudessem interagir usando ferramentas do blog. A responsabilidade de análise e inserção no acervo da Biblioteca do Câmpus Inhumas, dos materiais mapeados, foi repassada à coordenação de Biblioteca.

Após a busca no SIB/IFG, selecionamos material aberto digital na Internet, via Google. Como informado na metodologia, utilizamos movimentos retóricos para selecionar o material. Foram observados os seguintes critérios: (1) assunto, (2) publicação, (3) suporte, (4) identificação, (5) público-alvo e (6) autor(a) para o mapeamento dos materiais de química em formato digital e aberto. Segue o Quadro 2 para ilustrar a organização do material pesquisado:

Quadro 2: Exemplificação do material mapeado: fontes de pesquisa acesso aberto Área de química

\begin{tabular}{|c|c|c|c|c|c|}
\hline Assunto & Publicação & Suporte & Identificação & Público & Autor(a) \\
\hline $\begin{array}{l}\text { Química } \\
\text { Geral }\end{array}$ & $\begin{array}{l}2018 \\
\text { file:///C:/Users/Biblioteca/Downloads/G } \\
\text { uia PNLD 2018 Quimica.pdf }\end{array}$ & PDF & $\begin{array}{l}\text { PNLD_2018_ } \\
\text { Química }\end{array}$ & $1^{\circ}$ ano & $\begin{array}{l}\text { Ministéri } \\
\text { o da } \\
\text { Educaç } \\
\text { ão }\end{array}$ \\
\hline $\begin{array}{l}\text { - } \\
\text { desiosida } \\
\text { química; } \\
\text {-Química } \\
\text { geral; } \\
\text { - } \\
\text { Químicos; } \\
\text {-Química } \\
\text { no }\end{array}$ & $\begin{array}{l}\text { Sem data. } \\
\text { https://www.professoramanuela.com.br } \\
\text { /livros.html }\end{array}$ & Online & Paradidáticos & $\begin{array}{l}1^{\circ}, 2^{\circ} \text { e } \\
3^{\circ} \text { ano }\end{array}$ & \begin{tabular}{|l} 
Manuela \\
Lustosa \\
Diniz
\end{tabular} \\
\hline
\end{tabular}


Revista Brasileira da Educação Profissional e Tecnológica, v. 1, n. 20, e9790, 2021, p. 10 de 18 (CC BY 4.0) | ISSN 2447-1801 | DOI: https://doi.org/10.15628/rbept.2021.9790

\begin{tabular}{|c|c|c|c|c|c|}
\hline cotidiano. & & & & & \\
\hline Química I & $\begin{array}{l}2014 \\
\text { https://jucienebertoldo.files.wordpress. } \\
\text { com/2014/02/quimica1.pdf }\end{array}$ & PDF & Apostila & $1^{\circ}$ ano & $\begin{array}{l}\text { Juciene } \\
\text { Bertoldo }\end{array}$ \\
\hline Química & $\begin{array}{l}2015 \\
\text { https://www.youtube.com/watch?v= pT } \\
\text { i4WcPMhk }\end{array}$ & Online & Documentário & $\begin{array}{l}1^{\circ}, 2^{\circ} \mathrm{e} \\
3^{\circ} \text { ano }\end{array}$ & $\begin{array}{l}\text { Red } \\
\text { 9online }\end{array}$ \\
\hline $\begin{array}{l}\text { Radioativi } \\
\text { dade } \\
\text { nuclear }\end{array}$ & $\begin{array}{l}2014 \\
\text { https://www.youtub } \\
\text { e.com/watch?v=P8tqZrXu9zA }\end{array}$ & Online & $\begin{array}{l}\text { Vídeoaula } \\
\text { conceito e } \\
\text { exercício }\end{array}$ & $2^{\circ} a$ ano & Stoodi \\
\hline
\end{tabular}

Fonte: Elaboração própria.

O material mapeado apresenta, de modo geral, características que atraem os(as) nativos(as) digitais, como por exemplo, o material encontra-se disponível para ser acessado em qualquer dispositivo, conforme Santaella (2010); uso de imagem em movimento e acesso rápido pela internet de acordo com Coelho (2012); há também, desafio e temáticas envolvendo o cotidiano. Esse material foi disponibilizado no blog Boro, Bora estudar química, descrito na seção 4.2. Segue, no Gráfico 1, o quantitativo do material mapeado:

Gráfico 2: Quantidade e tipo de material mapeado

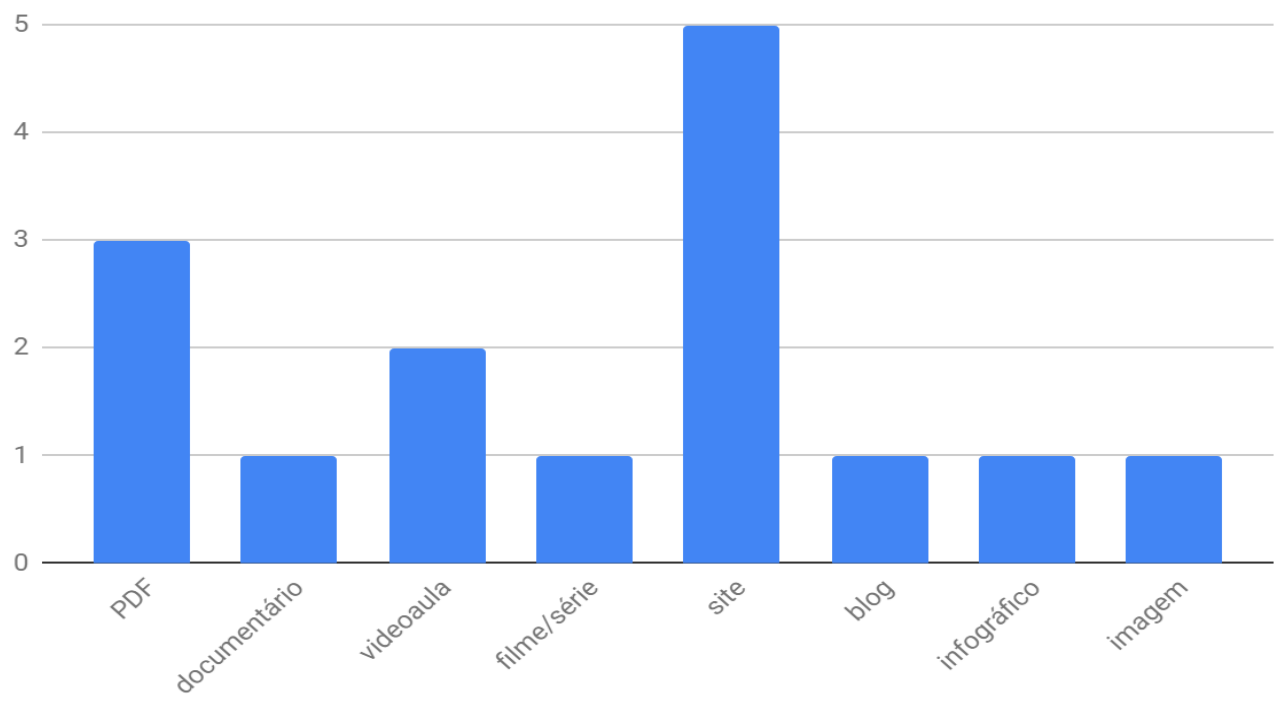

Fonte: Elaboração própria. 
Verificamos, a partir do Gráfico 1, um destaque para os materiais referentes aos textos no formato em PDF, disponíveis em sítios governamentais, e destacam os sítios com conteúdos de química geral. Contudo, há uma diversidade desses materiais disponível na rede. O arquivo em PDF e sítios são recursos que favorecem o compartilhamento da informação por bibliotecas (MARCONDES, KURAMOTO, TOUTAIN, SAYÃO, 2005). No entanto, há outros recursos que podem ser explorados pelas bibliotecas, como videoaulas, documentários, mapas mentais. O quantitativo de sítio também desperta a atenção. Esse recurso, em maior quantidade, pode indicar maior aceitação do/a usuário/a pela acessibilidade, com "um clique" pode ter em mãos várias informações, sem a necessidade de baixar arquivo, abrir e armazenar em alguma pasta no computador ou dispositivo móvel.

No que se refere à videoaula, destacamos dois exemplares, pelos conteúdos e apresentação, mas também estão presentes abundantemente na Internet. Passamos à criação do blog.

\subsection{DA CRIAÇÃO E AVALIAÇÃO DO BLOG}

A escolha pelo uso do blog ocorreu pelas características dessa ferramenta digital. Ela permite a interatividade, a organização criativa do ambiente virtual e, também, pela gratuidade. Ainda, o blog foi uma opção para promover a pesquisa colaborativa entre as pesquisadoras e o/a usuário/a do recurso desenvolvido. Constituindo mais que um repositório, um espaço de troca, de diálogo. $O$ funcionamento de outros blogs e o que era necessário para mantê-los, como séries, filmes, documentários entre outros, contribuíram para a construção do Boro, bora estudar química.

Para criação do blog, adotamos dois procedimentos. Primeiro, buscamos na bibliografia do Curso Técnico Integrado Integral em Química, no catálogo eletrônico do SIB/IFG e no Google a existência de materiais no formato digital para disponibilizar, como: vídeos, e-book, arquivo em PDF, dentre outros. Concluído esse procedimento, inserimos os materiais no blog. Destacamos que a escolha do nome do repositório relaciona-se com o estudo da química, fazendo um jogo de palavras do elemento químico Boro e a expressão "bora", redução coloquial de "vamos embora".

Além do formato do material para constituição do acervo, seguimos os critérios de escolha do InfoEnem (2012), que julga imprescindível, considerar:

a) o conteúdo: diz respeito à quantidade e qualidade do material (listas de exercícios, dicas, curiosidades etc.);

b) a navegação: tem relação com a divisão, disposição do conteúdo no site e velocidade de acesso;

c) a aparência: consiste na organização da página, como cores utilizadas, quantidade de anúncios de publicidade, logotipo (se houver), disposição do cabeçalho, corpo e rodapé; 
d) interatividade: envolve a parte do conteúdo que promova maior entretenimento, como jogos, videoaulas, apresentações com animações etc.;

e) as atualizações: refere-se à frequência com que os sites publicam notícias e artigos, assim como atualizam dados de suas páginas.

O InfoEnem (2012) destacou blogs e sítios de importância na pesquisa de química que foram relacionados e indicados no blog criado durante o desenvolvimento da pesquisa (https://boraestudarquimica.blogspot.com/). Ressaltamos que os blogs têm como principal característica trazer artigos relacionados às disciplinas, para estudo complementar. De uma forma geral, esses espaços não oferecem grande quantidade de conteúdos, entretanto compensam com a qualidade, trazendo leituras complementares e mais específicas (InfoEnem, 2012).

Para esta pesquisa, o blog Boro, Bora estudar química foi disponibilizado, em 29 de abril de 2019, na rede como ilustra a Figura 2:

Figura 2: Print da página de abertura do blog.

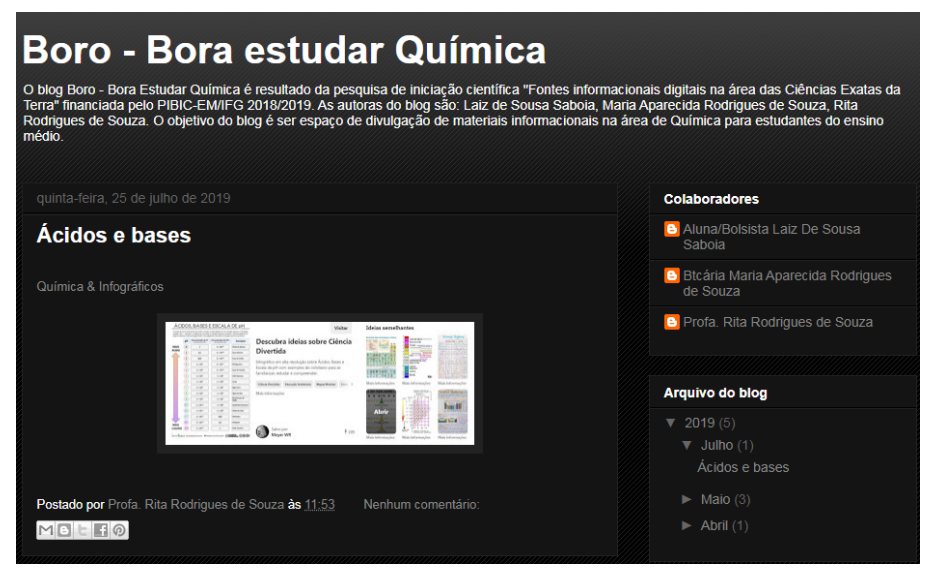

Fonte: Elaboração própria

Em relação à apresentação técnico-científica, durante a III Feira de Ciências do IFG/Câmpus Inhumas (Figura 2), os/as participantes avaliaram o Blog como recurso educacional aberto com materiais na área de ensino de química. 
Figura 3: Apresentação da pesquisa para a coleta de dados.

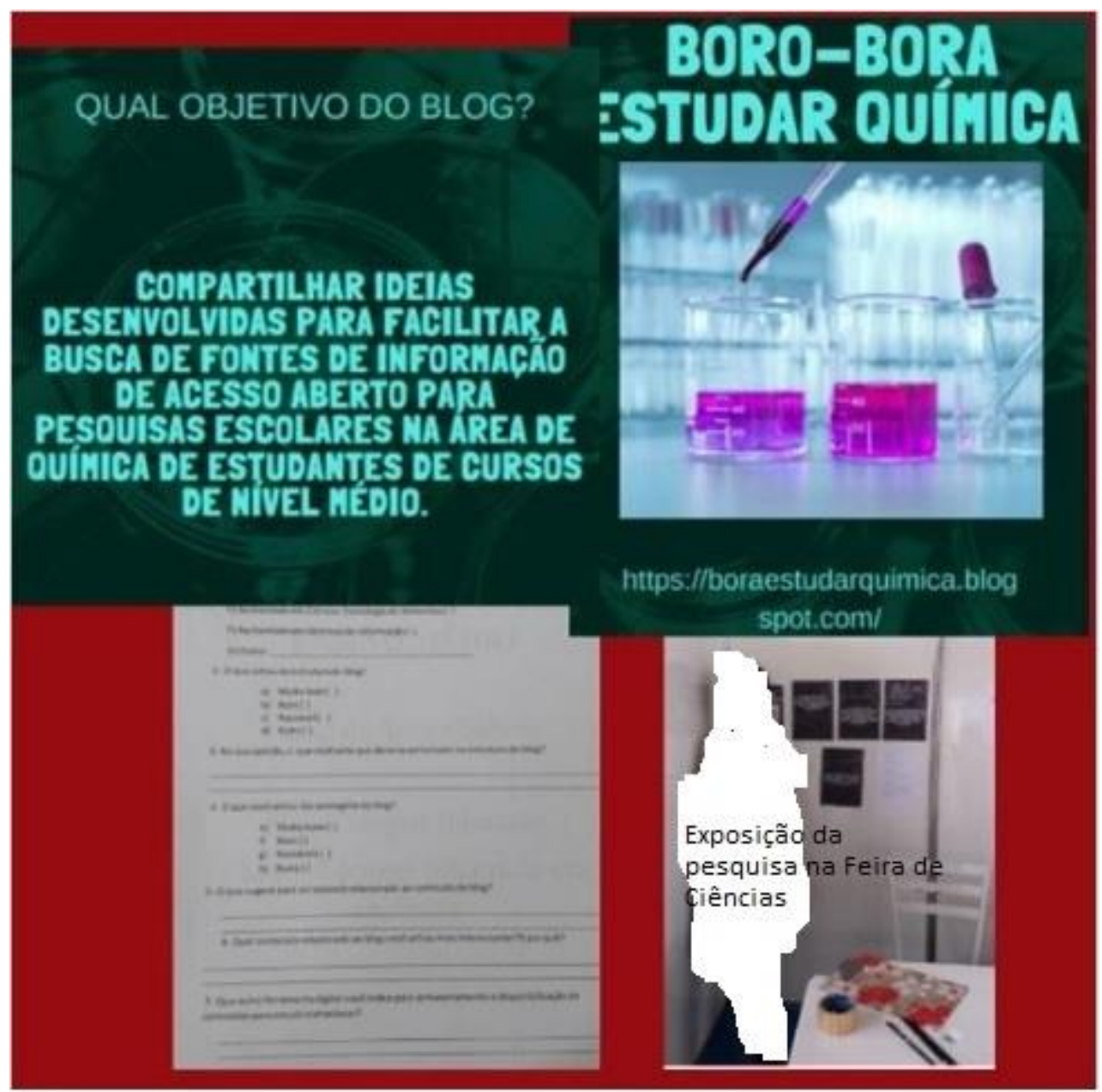

Fonte: Elaborado pelas pesquisadoras (2020)

Participaram da pesquisa 15 estudantes distribuídos entre os Cursos Técnico Integrado Integral em Química (9), Técnico Integrado Integral em Informática (1), Bacharelado em Sistemas de Informação (1), Técnico Integrado Integral em Agroindústria (1), Bacharelado em Ciência e Tecnologia de Alimentos (1), Licenciatura em Química (2) e professores (1). A avaliação da estrutura do blog pelos participantes foi considerada como "muito bom" (11) "bom" (5). No entanto, na opinião deles, na estrutura do blog deveria:

a) colocar abas de indicação de conteúdos presentes no blog, aba com os favoritos do público;

b) inserir mais filmes e séries;

c) incluir postagens abertas;

d) buscar uma interface mais agradável para os usuários;

e) tornar mais acessível para usuários leigos;

f) utilizar mecanismos de diferentes assuntos, sendo acessível a diversas pessoas; 
g) divulgar mais vídeo aula experimental, curiosidades, resumo, pré-provas, exercícios para melhor absorção dos conteúdos, resoluções de questões Enem;

h) tornar algo mais chamativo para os jovens;

i) evidenciar as mulheres que trabalham no ramo;

j) utilizar mais vídeos e posts.

Podemos observar, pelas respostas dos participantes, uma ratificação do que Prensky (2001), Santaella (2010) e Coelho (2012) discutem sobre a geração dos/as nativos/as digitais a reivindicação de recursos das TDIC para serem utilizados no processo ensino e aprendizagem. Esse aspecto fica evidente, por exemplo, pela solicitação de mais recursos que permitam rapidez no acesso, interação virtual, contemplem a diversidade e as diferenças individuais e que apresentem conteúdos em diferentes linguagens.

Os/As participantes, ao avaliarem as postagens no blog, consideraram "muito boas" (9) e "boas" (7). Eles, contudo, sugerem que sejam postados no repositório Boro, bora estudar química conteúdos relacionados a:

a) resumos de matérias;

b) dicas de estudo;

c) posts do grupo PS Química, superinteressante;

d) exercícios resolvidos;

e) séries e filmes relacionados a matéria de química;

f) nomenclaturas;

g) artigos explicando questões do Enem;

h) assuntos relacionados à composição das maquiagens;

i) mapas mentais que facilitam nos estudos;

j) vídeos aulas de professores explicando os conteúdos;

k) química dos cabelos.

As sugestões dos/as participantes revelam uma tendência à praticidade, à síntese, à economia e à contextualização dos temas de química com o entorno da vida do jovem. Isso confirma a crítica de Coelho (2012) que os/as nativos/as digitais optam unicamente pela realização de pesquisa utilizando as TDIC, cabendo ao professorado e demais agentes educativos a ressignificação do papel formativo. São, evidentemente, sugestões pertinentes, entretanto, o aprendizado e a construção do conhecimento passam por processos pelos quais exigem tempo, dedicação, esforço 
e maturidade. Permear, esse processo, com diferentes procedimentos pedagógicos em todos os âmbitos e ambientes da escola constitui uma necessidade e responsabilidade dos agentes educacionais.

É um caminho a percorrer. A construção de novos modelos de espaços de conhecimentos, descritos por Lévy (1999), demanda pesquisa científica, experimentos didáticos inovadores, mudanças no funcionamento-base do sistema escolar. Esse autor nos apresenta, consistentemente, uma pista de como usar as tecnologias observando o tempo atual delas.

Os conteúdos que os/as participantes sugerem ser postados no blog Boro, bora estudar química, na ocasião da pesquisa, foram:

a) lista de exercícios;

b) filme;

c) a série Breaking Bad, que aborda diversos conteúdos da química;

d) questões voltadas para o Enem e vestibular;

e) resolução de dúvidas;

f) exercícios de maior dificuldade;

g) apresentação de como fazer sabão;

h) ácidos e bases, pois são conteúdos difíceis;

i) a apresentação da química perto de você, proporciona uma aproximação da química com atividades rotineiras.

A teoria deve caminhar junto com a prática, na concepção dos participantes. Ao disponibilizar recursos educacionais abertos os responsáveis por essa postagem devem observar a organização teórica proposta por Souza (2017). Os participantes indicaram algumas TDIC para armazenamento e disponibilização de conteúdos para estudo extraclasse. As ferramentas citadas foram: aplicativo para celular; canal youtube, redes sociais (instagram, facebook, twitter), site vinculado a um perfil no instagram. Em nenhum momento os participantes destacaram o papel da biblioteca na constituição de um acervo digital para facilitar ou mediar o processo de acesso à informação, conforme postulam Marcondes, Kuramoto, Toutain e Sayão (2005). Cabe aqui indagar sobre o porquê desse "apagamento". Essa pesquisa não consegue responder a esse questionamento, mas incita a necessidade de se pesquisar sobre essa indagação.

Das sugestões dos professores, que participaram da pesquisa, destacamos a necessidade se ter participação de profissionais da área de Química para validar as fontes encontradas. Todas as sugestões foram acolhidas de modo que o blog pudesse ter um alcance maior, como o acesso dele pelo Google e por outros aplicativos. O blog está em circulação com postagem de conteúdos selecionados durante a pesquisa. 
A experiência foi exitosa. Conseguimos aprender, colaborativamente, novos propósitos de (re) uso dos recursos informacionais abertos e desenvolver uma ferramenta digital para auxiliar os estudos de química de estudantes do ensino médio. Essa experiência pode se estender a outras áreas do conhecimento e integrar-se às práticas de trabalho das bibliotecas escolares.

\subsection{DA REFLEXÃO SOBRE A AÇÃO INVESTIGATIVA/EXPERIMENTAL EMPREENDIDA}

Para Lévy (1999), devemos "acompanhar consciente e deliberadamente uma mudança de civilização que questiona profundamente as formas institucionais, as mentalidades e a cultura dos sistemas educacionais tradicionais e sobretudo os papéis de professor e de aluno" (LÉVY, 1999, p.174. Grifo do autor). Aqui, agregamos também, a necessidade de mudança das bibliotecas e dos/as agentes educacionais que nelas atuam direta ou indiretamente, assim como pontuam Marcondes, Kuramoto, Toutain e Sayão (2005) acerca do papel de uma biblioteca digital.

A pesquisa e a proposição/avaliação do blog constituíram uma experiência de crescimento intelectual e amadurecimento acerca da aplicação desse tipo de ferramenta como repositório e compartilhamento de dados. Para as pesquisadoras (docente, bibliotecária e discente) do Programa Institucional de Bolsa de Iniciação Científica do Ensino Médio (PIBIC-EM), foi motivador e contribuiu para a construção de conhecimentos.

\section{CONSIDERAÇÕES FINAIS}

Para além da disponibilização, há a necessidade de formar estudantes que saibam encontrar e, bem usar, informações e transformá-las em conhecimentos úteis à atuação deles nos contextos escolar, social, político e econômico que os cercam. Assim, a experiência de pesquisa de mapeamento de recursos abertos na área de química, criação e divulgação do blog Boro, bora estudar química contribuiu tanto para compreensão das necessidades desse público quanto para identificar lacunas que estão se constituindo no âmbito de material teórico, dessa área de conhecimento, de adaptação aos recursos tecnológicos digitais.

O uso de TDIC em contexto familiar ou de entretenimento requer habilidades distintas do uso acadêmico e profissional, há a necessidade de adaptação aos contextos de uso. O/A jovem precisa ter (in)formação nesse sentido. O IFG/Câmpus Inhumas, pelos dados obtidos, em termos de recurso humano apresenta-se em vantagem, contudo, falta-lhe recurso material. É mister aprofundar na compreensão da política institucional para que o trabalho da biblioteca viabilize o acesso e educação científica para jovens do ensino médio. 
A pesquisa realizada evidencia a necessidade de investimento institucional em acervo digital e formação docente e discente para o uso digital, com propósitos técnico-científicos e acadêmicos, bem como, utilizar o potencial de trabalho e qualificação dos servidores da Biblioteca Atena para o fomento de práticas inovadoras de disseminação de recursos digitais abertos à comunidade acadêmica.

A inexistência de ambiente de pesquisa com fontes de informação, no formato digital, especializado para o público de nível médio é um problema para o desenvolvimento de pesquisa científica, bem como a falta de uma educação científica direcionada especificamente para esse público. Cria-se uma situação insustentável do ponto de vista pedagógico pois, de um lado o/a nativo/a digital com habilidades e competências apropriadas para certos contextos de uso e, de outro, a escola e seus segmentos com uma prática didático-pedagógica consolidada de acordo com tecnologias distantes desse sujeito.

A experiência com o blog Boro, bora estudar química aponta para uma possibilidade tecnológica digital de trabalhar para suprir certas lacunas em relação ao desenvolvimento práticas de estudo e pesquisa para o público do ensino médio.

\section{REFERÊNCIAS}

AMIEL, T.; OREY, M.; WEST, R. Recursos Educacionais Abertos (REA): modelos para localização e adaptação. ETD - Educ. Tem. Dig., Campinas, v. 12, n. esp., p. 112-125, mar. 2011.

BRASIL. Congresso Nacional. Lei no 11.892, de 29 de dezembro de 2008. Brasília: Planalto. Disponível em: www.planalto.gov.br/ccivil 03/ ato20072010/2008/lei/l11892.htm. Acesso em: 10 mar. 2020.

COELHO, P. M. F. Os nativos digitais e as novas competências tecnológicas. Texto Livre: Linguagem e Tecnologias, v. 5, n. 2, p. 88-95, 2012. Disponível em: http://www.periodicos.letras.ufmg.br/index.php/textolivre/article/viewFile/2049/7254. Acesso em: 05 mar. 2020.

INSTITUTO PRÓ-LIVRO. Retrato de leitura no Brasil: 4. ed. Brasília: Ibope Inteligência, 2016. Disponível em:

http://prolivro.org.br/home/images/2016/Pesquisa Retratos da Leitura no Brasil 2015.pdf. Acesso em: 14 jun. 2019.

LÉVY, P. A nova relação com o saber. In: LÉVY, P. Cibercultura. Tradução: Carlos Irineu da costa. São Paulo: Editora 34. 1999. p. 159-170.

MARCONDES, C. H.; KURAMOTO, H.; TOUTAIN, L. B.; SAYÃO, L. (Org.)

Bibliotecas digitais saberes e práticas. Salvador, BA: EDUFBA; Brasília: IBICT, 2005. 
OS 10 melhores sites e blogs de Química do Brasil. InfoEnem, 22 fev. 2012.

Disponível em: https://www.infoenem.com.br/os-10-melhores-sites-e-blogs-dequimica-do-brasil/. Acesso em: 20 fev.. 2020.

PRENSKY, M. Digital Native, digital immmigrants. On the horizon, MCB University Press, v. 9, n. 5, October, 2001. Disponível em:

http://www.marcprensky.com/writing/Prensky\%20-

\%20Digital\%20Natives,\%20Digital\%20Immigrants\%20-\%20Part1.pdf. Acesso em: 07 mar. 2020.

SANTAELLA, L. A ecologia pluralista da comunicação: conectividade, mobilidade, ubiquidade. São Paulo: Paulus, 2010.

SEVERINO, A. J. Métodos de estudo para o 2o grau. São Paulo: Cortez, 1994.

SOUZA, M. A. R.; OLIVEIRA, L. P. Letramento informacional com uso de recursos educacionais abertos: estudo em bibliotecas de instituições de educação profissional, científica e tecnológica da Região Centro-Oeste. In: GOMES, S. H. A, SANTOS, A. P., REIS, F.; OLIVEIRA, F. R. (Orgs.). Letramento Informacional: educação para informação. Goiânia: Gráfica UFG, 2016. p. 261-280. Disponível em: https://cafecomleitura.fic.ufg.br/up/366/o/E-book CELI (Corrigido).pdf. Acesso em: 20 abr. 2020.

SOUZA, R. R. Leitura e escrita de resumo escolar no ensino médio: da teoria de gênero textual à prática pedagógica. Jundiaí, SP: Paco, 2017. 